\title{
Analytical methods for quality and quantity control of food supplements, containing caffeine
}

\author{
Papanov S. ${ }^{1}$, Pankova S. ${ }^{2}$, Ivanov K. ${ }^{1}$, Ivanova S. ${ }^{1}$, Doncheva D. ${ }^{2}$, Pencheva I. ${ }^{2}$ \\ ${ }^{1}$ Medical University Plovdiv, Faculty of Pharmacy, Dept. of Botany and Pharmaceutical chemistry, Plovdiv, Bulgaria \\ ${ }^{2}$ Medical University Sofia , Faculty of Pharmacy, Dept. of Pharmaceutical chemistry, Sofia, Bulgaria
}

\section{Email address:}

stoyan.papanov@abv.bg (S. Papanov)

\section{To cite this article:}

Papanov S., Pankova S., Ivanov K., Ivanova S., Doncheva D., Pencheva I.. Analytical Methods for Quality and Quantity Control of Food Supplements, Containing Caffeine. International Journal of Nutrition and Food Sciences. Special Issue: Taurine and Caffeine Supplementation in Energy Food Drinks: Uses, Side Effects and Quality Control. Vol. 4, No. 1-1, 2015, pp. 14-17. doi: 10.11648/j.ijnfs.s.2015040101.13

\begin{abstract}
Many beverages such as soft drinks, coffee and tea contain the mild stimulant caffeine $\left(\mathrm{C}_{8} \mathrm{H}_{10} \mathrm{~N}_{4} \mathrm{O}_{2}\right)$. The caffeine content varies widely from about $100 \mu \mathrm{g} / \mathrm{mL}(100 \mathrm{ppm})$ in sodas to over $1000 \mu \mathrm{g} / \mathrm{mL}$ in certain types of coffee. For this reason the caffeine and the content in they need to be analyzed. A rapid and selective high-performance liquid chromatographic (HPLC) method is developed for the separation and determination of caffeine.
\end{abstract}

Keywords: Caffeine, HPLC, Quality, Control

\section{Introduction}

Recently the pharmaceutical and food industries produce a large number of supplements and products which contain caffeine. Xanthine derivate caffeine (CF), 1, 3, 7-trimethylxanthine, is widely found in the human diet. These compound naturally occurs in many food products such as tea, coffee, and cocoa beans, being the most abundant xanthine in chocolate $(1,2)$. Caffeine plays an important role in human nutrition and health maintenance. Due to the large consumption of caffeine and the production capacity requirements are constantly increasing. This paper reviews the methods for the quality and quantity control of food and supplements, containing caffeine (1, 2-10).

The main objective of this study is to produce a quick and reproducible method for the routine, simultaneous analyses of $\mathrm{CF}$, in food, drinks, and herbal products $(1,11-19)$.

\section{Material and Methods}

\subsection{Material}

All solvents and reagents were of analytical grade unless indicated otherwise. The solutions were prepared with deionized water. The standards of $\mathrm{CF}$, were obtained from Sigma. Acetonitrile and methanol (HPLC grade) were obtained from Sigma. Chloroform and tetrahydrofurane (THF) were HPLC grade, obtained from Sigma.

\subsection{Real Samples}

The natural products: black tea, green tea, Nescafe, coffee, cocoa powder.

Different energy drinks and beverages: Redbull, Pepsi, Coca Cola, Derby Cola, Shark, Pitbull, Party Cola.

\subsection{Equipment}

The chromatographic procedure was carried out using: Liquid chromatograph Shimadzu LC - 10 Advp equipped with 4.6 x $250 \mathrm{~mm}$ column Luna 5U C18 (2) 100 A, Phenomenex ODS with particle size $5 \mu \mathrm{m}$;

Detector SPD 10 AVvp - UV-VIS with fixed analytical wave lengths.

\subsection{Chromatographic Conditions}

Isocratic mobile phase, prepared by mixing of filtered and degassed Acetonitril / Phosphate buffer (35:65 v/v)

- $226 \mathrm{~nm}$ analytical wavelength;

- Column temperature $25^{\circ} \mathrm{C}$;

- Flow rate about $1.5 \mathrm{ml} / \mathrm{min}$.

\subsection{Procedure}

In reversed phase HPLC water is considered a "weak" chromatographic solvent and organic solvents such as 
methanol are considered "strong" chromatographic solvents. A typical methods development procedure for HPLC starts with elution using a strong solvent to elute all components in a mixture quickly. In a series of isocratic runs, weaker solvents are blended in with the strong solvent to achieve resolution of the components of interest $(1-10,17,22)$.

\subsection{Calibration Standards}

Devise a plan for making a series of dilutions to prepare 4 calibration standards with concentrations from 20 to 100 $\mu \mathrm{g} / \mathrm{mL}$ starting with the $1000 \mu \mathrm{g} / \mathrm{mL}$ caffeine standard. Use only your $10-\mathrm{mL}$ and $25-\mathrm{mL}$ volumetric flasks and HPLC grade water for the dilutions. Store each solution tightly capped in a labeled $15-\mathrm{mL}$ vial (1).

The working standard solutions $(0.2-10.0 \mu \mathrm{L})$ of $\mathrm{CF}$ were injected into the HPLC, and the peak area responses were obtained. A method of the external standard calibration was used. The separation of the standard mixture of CF using the method described is shown in Figure 1. The linear standard curves for $\mathrm{CF}$ were obtained separately by plotting concentration versus area.

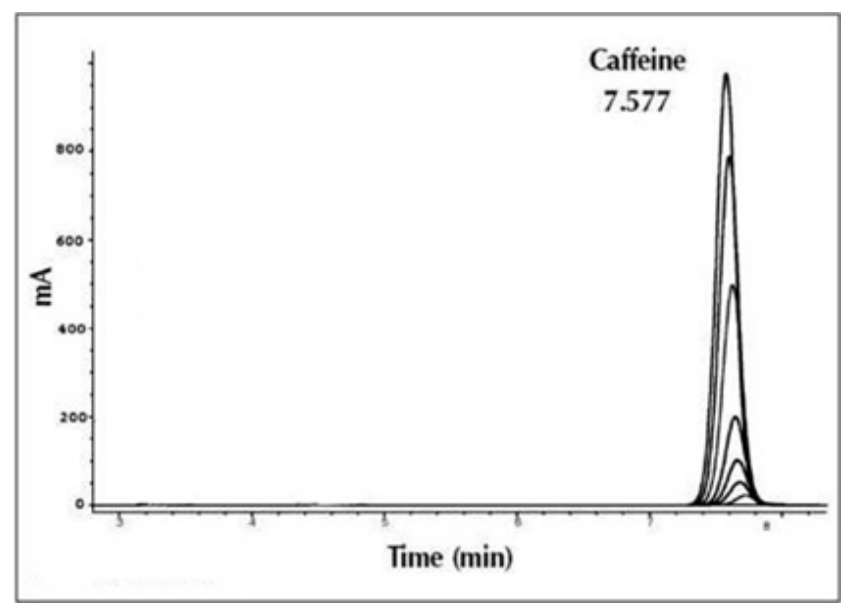

Figure 1. Chromatograms of working stock solution

\subsection{Preparation of Caffeinated Beverage}

Obtain a sample for which you wish to measure the caffeine content. If choose a carbonated beverage, your sample must be degassed before injection.

\subsection{Analysis of Caffeine in Beverages}

Reverse phase HPLC is used to determine the concentration of caffeine in coffee, tea, and soft drinks. The traditional method for the determination of caffeine is via extraction with spectrophotometric quantitation. Use of the liquid chromtography system permits a fast and easy separation of caffeine from other substances such as tannic acid, caffeic acid, and sucrose found in these beverages. Five standard solutions of caffeine are prepared and in injected into the HPLC. In addition, the beverages coffee, decaffeinated coffee, tea, and caffeine containing soft drinks are prepared as indicated in the following section and injected into the HPLC. From the resulting chromatograms, measurements of retention time, $t R$, and peak areas are made. If the flow rate and pump pressure are held constant throughout the entire experiment, tR may be used as a qualitative measure and the peak area as a quantitative measure. A calibration curve for peak area against concentration of the caffeine standards can then be employed to determine the concentration of caffeine in the four beverages. The solvent (mobile phase) in this experiment is $47 \%$ methanol / $53 \%$ water $(1,2,5)$.

\subsection{Sample Preparation and Extraction}

The water extracts of a black tea $(5.00 \mathrm{~g})$ and green tea $(5.00 \mathrm{~g})$ were made by mixing for $30 \mathrm{~min}$ in hot water $(200 \mathrm{~mL}$, first boiled) in a thermal flask on the magnetic stirrer. The extracts were then filtered through a filter paper to remove the particulate matter. Ten milliliters of filtrate, adjusted to $\mathrm{pH} 8$ with $0.1 \mathrm{M} \mathrm{NaOH}$, were subjected to the cleanup procedure. The coffee powder samples were weighed $(5 \mathrm{~g})$ and extracted with boiling hot water $(200 \mathrm{~mL})$ by mixing in the thermal flask for $10 \mathrm{~min}$ on the magnetic stirrer. The extracts were then filtered through the filter paper to remove the particulate matter. Ten milliliters of filtrate, adjusted to $\mathrm{pH} 8$ with $0.1 \mathrm{M}$ $\mathrm{NaOH}$, were subjected to the cleanup procedure as described later. The cocoa powder $(5 \mathrm{~g})$, were filled up to $200 \mathrm{~mL}$ with water in a plastic container and extracted for $40 \mathrm{~min}$ at $45^{\circ} \mathrm{C}$ in the ultrasonic bath $(1,5,15,18,19)$.

The extracts were then filtered through the filter paper to remove the particulate matter. Ten milliliters of filtrate, adjusted to $\mathrm{pH} 8$ with $0.1 \mathrm{M} \mathrm{NaOH}$, were subjected to the clean-up procedure.

The samples of fizzy drinks were degassed for $25 \mathrm{~min}$ in an ultrasonic bath to release the $\mathrm{CO} 2$. Prior to the analysis, the samples were adjusted to $\mathrm{pH} 8$ with $0.1 \mathrm{M} \mathrm{NaOH}$, filtered through a $0.20-\mu \mathrm{m}$ nylon filter, and injected directly into the $\operatorname{HPLC}(1,9)$.

\section{Discussion}

The development of the method was based on the experience obtained from the methods previously developed for the analysis of $\mathrm{CF}$ and some other compounds of interest (1-9). Of the columns tested (Hypersil ODS C18 $100 \times 4.6$ $\mathrm{mm}$, Cosmosil C18 $150 \times 4.6 \mathrm{~mm}$, Cosmosil C18 $250 \times 4.6$ $\mathrm{mm}$, Phenomenex Luna $5 \mu \mathrm{m} \mathrm{C8} 150 \times 4.6 \mathrm{~mm}$, Phenomenex Luna $5 \mu \mathrm{m} \mathrm{C8} 250 \times 4.6 \mathrm{~mm}$, and Zorbax Eclipse XDB-5 $\mu \mathrm{m}$ C8 column $150 \times 4.6 \mathrm{~mm}$ ), it was only by using the Zorbax Eclipse XDB-5 $\mu \mathrm{m} \mathrm{C8}$ column $150 \times 4.6 \mathrm{~mm}$ that a good separation for $\mathrm{CF}$.

The effect of the flow rate and the composition of the mobile phase on the retention time (tR), the peak width (W50), for $\mathrm{CF}$ were studied using the working standard solution.

The injection volume of the working standard solution was $5 \mu \mathrm{L}$, and the column temperature was at $25^{\circ} \mathrm{C}$. The combination of $0.8 \mathrm{~mL} / \mathrm{min}$ flow rate and water-THF $(0.1 \%$ THF in water, $\mathrm{pH} 8)$-acetonitrile $(90: 10, \mathrm{v} / \mathrm{v})$ as the mobile phase is selected as a compromise between the analyte retention time (sampling rate), separation efficiency (number of theoretical plates), and the consumption of solvents $(1,25)$. 


\subsection{Validation of the HPLC Method}

We studied the selectivity (different samples with different matrices) and linearity in the range of 0.5 to $300 \mathrm{mg} / \mathrm{L}(0.5$, $1.0,3.0,5.0,10.0,25.0,50.0,75.0,100.0,125.0,150.0,250.0$, and $300.0 \mathrm{mg} / \mathrm{L}$ ). Also studied were the results of the assay, and limit of detection (LOD - signal to noise $[\mathrm{S} / \mathrm{N}]$ ratio 3:1), and limit of quantitation. There was no interference in the HPLC results by the matrices ingredients in any of the tested samples, which indicates that the methods are selective (Fig. 2).

The accuracy of the method was determined by analyzing the solutions of the known concentrations (the working standard solutions) and comparing the measured and known values $(1,2)$.
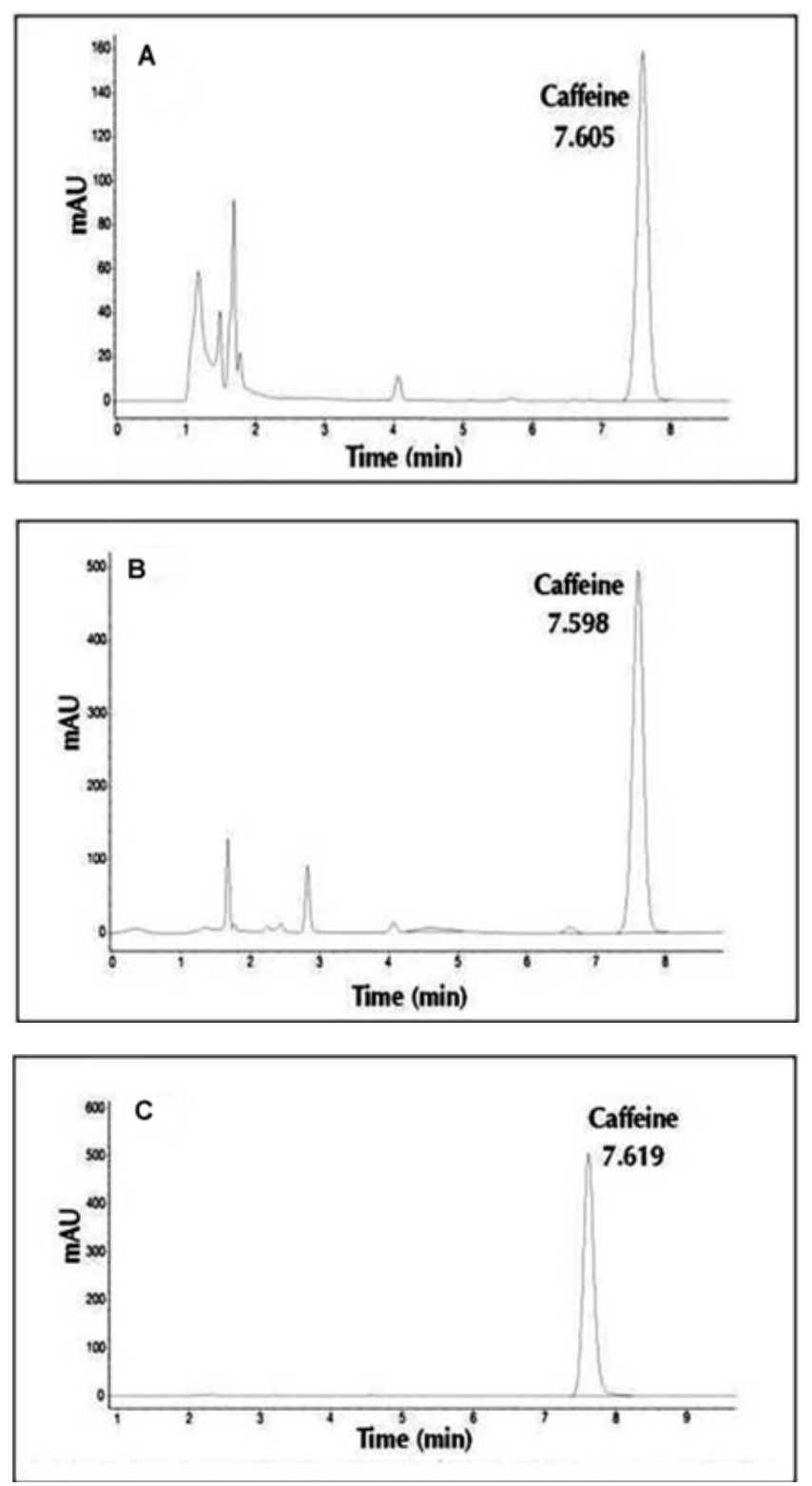

Figure 2. Chromatograms of some real samples under the optimized conditions, at $273 \mathrm{~nm}$. Mobile phase was water - THF (0.1\% THF in water, pH8) - acetonitrile $(90: 10, v / v)$, flow rate was $0.8 \mathrm{~mL} / \mathrm{min}$, column temperature was $25^{\circ} \mathrm{C}$ : Coca cola (A), Red Bull (B), Pitbull(C).
A repeatability test was performed to determine an intra-day variation in the peak's areas and retention times. The highest value for relative standard deviation (RSD) was $0.84 \%$ $(\mathrm{n}=6)$, which indicates that repeatability of the method is acceptable.

An intermediate precision was evaluated over three days (inter-day repeatability) using the working solution. This solution $(0.2-10.0 \mu \mathrm{L})$ was injected daily under the same conditions and the results were used for the repeatability study. The solution was stored at room temperature $\left(25 \pm 2^{\circ} \mathrm{C}\right)$ in sunlight $(1,3,7,12,18)$.

\section{Results}

The contents of CF obtained from the measurement of the numerous different samples of food, beverages, and natural products are shown in Table 1. These results show a strong correlation between the declared and determined values of $\mathrm{CF}$ for all analyzed samples, which implies a high efficacy and selectivity of the method used. The use of $\mathrm{C} 8$ column packing results in a better resolution, intensity, shape, and symmetry. The run time for the analysis is less than $8 \mathrm{~min}$. The lowest concentration that can be quantitated (LOQ) with an acceptable accuracy and precision and it was $0.2 \mathrm{mg} / \mathrm{L}$ for CF respectively. Furthermore, the LOD defined as $0.07 \mathrm{mg}$ of $\mathrm{CF}$ /L(1,20-25).

Table 1. Application Results for Natural Products, Beverages, and Food Samples

\begin{tabular}{lcc}
\hline \multirow{2}{*}{ Beverage and food samples } & Found values & Declared values \\
\cline { 2 - 3 } & CF & CF \\
\hline Coca cola $(\mathrm{mg} / \mathrm{L})$ & 106.7 & $\leq 150$ \\
Derby coca $(\mathrm{mg} / \mathrm{L})$ & 112.0 & $\leq 150$ \\
Red bull $(\mathrm{mg} / \mathrm{L})$ & 301.8 & $\leq 320$ \\
Pitbull $(\mathrm{mg} / \mathrm{L})$ & 230.1 & $\leq 250$ \\
Party cola $(\mathrm{mg} / \mathrm{L})$ & 101.2 & $\leq 150$ \\
Pepsi $(\mathrm{mg} / \mathrm{L})$ & 118.0 & $\leq 150$ \\
Shark $(\mathrm{mg} / \mathrm{L})$ & 349.0 & $\leq 350$ \\
Green tea $(\mathrm{mg} / 100$ g of sample) & 1301.1 & n.d. \\
Black tea $(\mathrm{mg} / 100$ g of sample) & 989.7 & n.d. \\
Nescaffe $(\mathrm{mg} / 100$ g of sample) & 3582.1 & n.d. \\
Cocoa $(\mathrm{mg} / 100 \mathrm{~g}$ of sample) & 50.0 & n.d. \\
* n.d. $=$ not declared. & & \\
\hline
\end{tabular}

\section{Conclusion}

The present method was tested to measure the CF in food, beverages, and natural products. In this work a fast, accurate, and sensitive method was developed for the determination of $\mathrm{CF}$ in food, beverages, and natural products. The use of the SPE pretreatment for the samples and results of the recoveries for this procedure confirmed that there is no matrix effect, so the extracts can be assessed with a calibration curve set from the analytes aqueous standard. Finally, the data for sensitivity, accuracy, reproducibility, and high analysis frequency suggest that the proposed HPLC method could be used for a routine quality control of food, drinks, and herbal products. 


\section{References}

[1] Branislava Srdjenovic, Vukosava Djordjevic-Milic, Nevena Grujic, Rade Injac, and Zika Lepojevic. "Simultaneous HPLC Determination of Caffeine, Theobromine, and Theophylline in Food, Drinks, and Herbal Products" Journal of Chromatographic Science, Vol. 46,144-149, February 2008

[2] J.B. Thomas, J.H. Yen, M.M. Schantz, B.J. Porter, and K.E. Sharpless. Determination of caffeine, theobromine, and theohylline in standard reference material 2384, baking chocolate, using reversedphase liquid chromatography. J. Agric. Food Chem. 52: 3259-63 (2004).

[3] P.D. Tzanavaras and D.G. Themelis. Development and validation of a high-throughput high-performance liquid chromatography assay for the determination of caffeine in food samples using a monolithic column. Anal. Chim. Acta 581: 94-8 (2007).

[4] D. Satinsky, I. Neto, P. Solich, H. Sklenárova, M. Conceição, B.S. Montenegro, and A.N. Araújo. Sequential injection chromatographic determination of paracetamol, caffeine, and acetylsalicylic acid in pharmaceutical tablets. J. Sep. Sci. 27:529-36 (2004).

[5] M. Kartal. LC method for the analysis of paracetamol, caffeine and codeine phosphate in pharmaceutical preparations. J. Pharm. Biomed. Anal. 26: 857-64 (2001).

[6] F.L. Coco, F. Lanuzza, G. Micali, and G. Cappellano. Determination of theobromine, theophylline, and caffeine in by-products of cupuacu and cacao seeds by high-performance liquid chromatography. J. Chromatogr. Sci. 45: 273-5 (2007).

[7] D.D. Rio, A.J. Stewart, W. Mullen, J. Burns, M.E.J. Lean, F. Brighenti and A. Crozier. HPLC-MSn analysis of phenolic compounds and purine alkaloids in green and black tea. J. Agric. Food Chem. 52: 2807-15 (2004).

[8] C.I. Rodrigues, L. Marta, R. Maia, M. Miranda, M. Ribeirinho, and C. Maguas. Application of solid-phase extraction to brewed coffe caffeine and organic acid determination by UV-HPLC. J. Food Compost. Anal. 20: 440-8 (2007).

[9] M.R. Brunetto, L. Gutierrez, Y. Delgado, M. Gallignani, A. Zambrano, A. Gomez, G. Ramos, and C. Romero.Determination of theobromine, theophylline and caffeine in cocoa samples by a high-performance liquid cromatografphic method with on-line sample cleanup in a switching-column system. Food Chem. 100: 459-67 (2007).

[10] J.P. Naik. Imporoved high-performance liquid chromatography method to determine theobromine and caffeine in cocoa and cocoa products. J. Agric. Food Chem. 49: 6579-83 (2001).

[11] A.R. Khanchi, M.K. Mahani, M. Hajihosseini, M.G. Maragheh, M. Chaloosi, and F. Bani. Simultaneous spectrophotometric determination of caffeine and theobromine in Iranian tea by artificial neural networks and its comparison with PLS. Food Chem.103:1062-8 (2007)

[12] D.K. Sinhg and A. Sahu. Spectrophotometric determination of caffeine and theophylline in pure alkaloids and its application in pharmaceutical formulations. Anal. Biochem. 349: 176-80 (2006).
[13] M. Arenda and G. Morlock. Simultaneous determination of caffeine, ergotamine and metamizol in solid pharmaceutical formulation by HPTLC-UV-FLD with mass confirmation by online HPTLC-ESI-MS. J. Chromatogr. Sci. 45: 251-5 (2007).

[14] M.J. Ford, M.A. Deibel, B.A. Tomkins, and G.J. Van Berkel. Quantitative thin-layer chromatography-mass spectrometry analysis of caffeine using a surface sampling probe electrospray ionization tandem mass spectrometry system. Anal. Chem. 77:4385-9 (2005).

[15] M. Aranda and G. Morlock. Simultaneous determination of riboflavin, pyridoxine, nicotinamide, caffeine and taurine in energy drinks by planar chromatography-multiple detection with confirmation by electrospray ionization mass spectrometry. J. Chromatogr. A 1131: 253-60 (2006.)

[16] V.V. Khasanov, K.A. Dychko, T.T. Kuryaeva, G.L. Ryzhova, and E.V. Maltseva. A new procedure for caffeine determination Russ. J. Appl. Chem. 78: 1427-9 (2005).

[17] S. Armenta, S. Garrigues, and M.Guardia. Solid-phase FT-Raman determination of caffeine in energy drinks. Anal. Chim. Acta 547: 197-203 (2005).

[18] M.M. Paradkar and J. Irudayaraj. Rapid determination of caffeine content in soft drinks using FTIR-ATR spectroscopy. Food Chem. 78: 261-6 (2002).

[19] M.S. Bispo, M.C.C. Veloso, H.L.C. Pinheiro, R.F.S. De Oliveira, J.O.N. Reis, and J.B. De Andrade. Simultaneouos determination of caffeine, theobromine, and theophylline by High performance liquid chromatography. J. Chromatogr. Sci. 40: 45-8 (2002).

[20] United States Pharmacopoeia, 24th edition, NF 19, United States Pharmacopoeial Convention, Rockville, MD 2002.

[21] International Conference on Harmonization, guideline Q2A, Text on validation of analytical procedures. Federal Register $1995,60,11260$

[22] International Conference on Harmonization, guideline Q2B, Validation of analytical procedures: methodology. Federal Register 1997, 62, 27463.

[23] Y.V. Heyden, A. Nijhuis, J. Smeyers-Verbeke, B.G.M. Vandeginste, and D.L. Massart. Guidance for robustness/ruggedness tests in method validation. J. Pharm. Biomed. Anal. 24: 723-53 (2001).

[24] L. Peikova, I. Pencheva, B. Tzvetkova, Chemical stability-indicating HPLC study of fixed-dosage combination containing metoprolol tartrate and hydrochlorothiazide, Journal of Chemical and Pharmaceutical Research, 2013, 5(7):132-140.

[25] Analysis of drugs - derivatives of purine; Educational methodical manual for students from Faculty of Pharmacy. State Educational Institution of Higher Professional Education Nizhny Novgorod State Medical Academy of the Russian Federal Agency of Health and Social Development. Nizhny Novgorod 2008. 